\title{
Household Bargaining and Excess Fertility: An Experimental Study in Zambia
}

\section{Citation}

Ashraf, Nava, Erica Field, and Jean Lee. "Household Bargaining and Excess Fertility: An Experimental Study in Zambia." American Economic Review 104, no. 7 (July 2014).

\section{Published Version}

doi:10.1257/aer.104.7.2210

\section{Permanent link}

http://nrs.harvard.edu/urn-3:HUL.InstRepos:13348078

\section{Terms of Use}

This article was downloaded from Harvard University's DASH repository, and is made available under the terms and conditions applicable to Open Access Policy Articles, as set forth at http:// nrs.harvard.edu/urn-3:HUL.InstRepos:dash.current.terms-of-use\#OAP

\section{Share Your Story}

The Harvard community has made this article openly available.

Please share how this access benefits you. Submit a story.

Accessibility 


\title{
Online Appendix: Household Bargaining and Excess Fertility: An Experimental Study in Zambia
}

\author{
Nava Ashraf, Erica Field and Jean Lee
}

January 8, 2014

FOR ONLINE PUBLICATION

\section{Technical Appendix ${ }^{1}$}

\section{A. A Simple Dynamic Variant of the Main Paper's Framework}

In this subsection we briefly outline a variant of the conceptual framework presented in the main body that accounts for the fact that couples may use contraception so as to space births. The objective here is to replicate within the boundaries of the efficient contracting framework the observed pattern that contraception is sometimes not used even though both spouses agree that it would be ideal to have the next child in two years rather than now.

Outline. Suppose that $H$ and $W$ must decide whether to try to have a child either in this period or the next. Suppose further that the probability per period of having a child when not using contraception is equal to $p$. When instead using contraception the probability is zero. In terms of ex-post payoffs, $H$ enjoys payoff $\bar{u}_{H}$ when having a child in the second period and payoff $\underline{u}_{H}$ when having a child in the first period, where $\bar{u}_{H}>\underline{u}_{H}>0$. Similarly, $W$ enjoys payoff $\bar{u}_{W}$ when having a child in the second period and payoff $\underline{u}_{W}$ when having a child in the first period, where $\bar{u}_{W}>\underline{u}_{W}>0$. Finally, $H(W)$ suffers loss $L_{H}\left(L_{W}\right)$ when not having a child in neither periods, where $L_{H}, L_{W}<0$. To focus on the case of interest we assume that (i) in case the couple has a child in the first period it uses contraception in the second period and (ii) if the couple decides to use contraception it is always in the first period only (i.e. the couple tries to have a child in the second period). Payoffs have been chosen so that $H$ and $W$ both agree that having a child in the second period is preferable to having a child in the first period.

The couple faces the following choice. It may either choose to use injectables in the first period, and wait for the second period to try and have a child, or not use injectables and try starting from the first period to have a child (and try again in the second period if the first period is a failure).

\footnotetext{
${ }^{1}$ We are grateful to Charles Angelucci for his very helpful insights and excellent research assistance in this section.
} 
We first look at the case in which each spouse is risk neutral and then turn our attention to the case of risk aversion.

Risk Neutrality. Suppose, to begin with, that both spouses are risk neutral. If the couple uses injectables, expected payoffs are given by:

$$
\begin{gathered}
U_{H}=p \bar{u}_{H}+(1-p) L_{H}, \\
U_{W}=p \bar{u}_{W}+(1-p) L_{W} .
\end{gathered}
$$

If instead the couple does not use injectables, then expected payoffs are given by:

$$
\begin{gathered}
U_{H}=p \underline{u}_{H}+(1-p)\left(p \bar{u}_{H}+(1-p) L_{H}\right), \\
U_{W}=p \underline{u}_{W}+(1-p)\left(p \underline{u}_{W}+(1-p) L_{W}\right) .
\end{gathered}
$$

It is then pareto efficient not to use contraception so long as:

$p \underline{u}_{H}+(1-p)\left(p \bar{u}_{H}+(1-p) L_{H}\right)+p \underline{u}_{W}+(1-p)\left(p \underline{u}_{W}+(1-p) L_{W}\right)>p \bar{u}_{H}+(1-p) L_{H}+p \bar{u}_{W}+(1-p) L_{W}$,

which simplifies to:

$$
\underline{u}_{H}+\underline{u}_{W}>\left(p \bar{u}_{H}+(1-p) L_{H}\right)+\left(p \bar{u}_{W}+(1-p) L_{W}\right)
$$

and:

$$
\frac{\underline{u}_{H}+\underline{u}_{W}-\left(p \bar{u}_{H}+(1-p) L_{W}\right)-p \bar{u}_{W}}{(1-p)}>L_{H} .
$$

That is, if the husband's loss associated to not having a child is large enough, the pareto efficient decision for the couple is not to use contraception in the first period, even though both spouses agree that it is best to have a child in the second period than in the first.

Risk Aversion. We formalize risk aversion in the simplest possible way. Note first that when not using contraception the probability of not having a child is equal to $(1-p)^{2}$. When instead using contraception the probability is $(1-p)$. Let $\tau_{H}\left(\tau_{W}\right)$ be a parameter capturing the extent of risk aversion of $H(W)$. Suppose that $\tau_{H} \geq \tau_{W}$ but that otherwise $\underline{u}_{H}=\underline{u}_{W}=\underline{u}, \bar{u}_{H}=\bar{u}_{W}=\bar{u}$ and $L_{H}=L_{W}=L$. It is pareto efficient not to use contraception so long as: 


$$
2(p \underline{u}+(1-p)(p \bar{u}+(1-p) L))-\left(\tau_{H}+\tau_{W}\right)(1-p)^{2}>2(p \bar{u}+(1-p) L)-\left(\tau_{H}+\tau_{W}\right)(1-p),
$$

that is, so long as:

$$
\left(\tau_{H}+\tau_{W}\right)(1-p)>2((p \bar{u}+(1-p) L)-\underline{u}) .
$$

Whenever risk aversion is large enough, the risk of never having a child makes it pareto efficient for the couple to try and have a child from the first period onwards. As under risk neutrality, this is true even though both spouses agree that it is best to have a child in the second period than in the first.

\section{B. The Noncooperative Framework}

We present a simple non-cooperative framework to model the intra-household bargaining over fertility decisions presented in the Conceptual Framework section. To save on space, we consider only the long run version of this game, that is, we consider the situation in which $H$ has the right beliefs concerning the scope for moral hazard. We nevertheless also briefly comment on the implications for the experiment below.

The set-up is identical to that developed in the Conceptual Framework, except that now (i) $H$ and $W$ cannot reach binding agreements (i.e., each spouse's action is a best reply to the other spouse's action) and (ii) we let $H$ feel aggrieved and act as a difficult husband/shade $\left(a_{H}=b\right)$ or not $\left(a_{H}=g\right)$ depending on his level of suspicion concerning $W$ 's use of contraception (see below). In what follows, let $w$ be the probability of $W$ choosing $a_{W}=c$, conditional on the availability of a contraceptive technology, and let $h$ be the probability of $H$ choosing $a_{H}=b$.

When $\theta=0, H$ may feel aggrieved suspecting the wife uses contraception, and can have an incentive to shade (to be a difficult husband). ${ }^{2}$ Specifically, when he decides to shade, $H$ gets extra payoff of

$$
S\left(w^{e}, \alpha\right):=k \cdot\left(\operatorname{Prob}\left[a_{W}=c \mid w^{e}, \alpha, \theta=0\right]-\operatorname{Prob}\left[a_{W}=n \mid w^{e}, \alpha, \theta=0\right]\right),
$$

where $w^{e}$ is $H$ 's subjective belief over $w$. This roughly means that being a bad husband yields a psychological gain (cost) of $k$ proportional to his subjective probability of $W$ choosing $a_{W}=c\left(a_{W}=n\right)$. Let $h$ be the probability of $H$ being a difficult husband conditional on $\theta=0$. On the other hand, $W$ directly incurs a cost of $l$ whenever $H$ becomes a difficult husband. We assume $\bar{u}_{W}-l<0$, which means that $W$ prefers having a child and a good husband to having no child and a bad husband.

The timing of the game is as follows. Nature (randomly) chooses whether contraception is available or

\footnotetext{
${ }^{2}$ For this assumption, we draw both from the anthropological literature cited in the Context section, regarding the mistrust and suspicion that husbands feel in this environment, and from Hart and Moore (2008). Becoming a "difficult" husband in our setting is what Hart and Moore (2008) model as ex-post, uncontractible shading. In our setting, the informal contract offered makes clear the expectation of childbearing as part of the marital arrangement, a strong cultural norm. Fehr, Hart and Zehnder (2011) provide experimental evidence for aggrievement from contract expectations not being met.
} 
not. If it is available, $W$ chooses $a_{w} \in c, n$. Otherwise, she has no choice and takes $a_{W}=n$. Conditional on $a_{W}$, Nature draws $\theta$. $H$ observes $\theta$. If $\theta=1$, he confirms $a_{W}=n$ and thus takes $a_{H}=g$. Otherwise, $H$ chooses $a_{H} \in g, b$.

The expected payoff functions are

$$
\begin{aligned}
U_{W}(w, h) & =\operatorname{Prob}[\theta=0] \cdot\left(\bar{u}_{W}-h l\right)+\operatorname{Prob}[\theta=1] \cdot 0-w K \\
& =w \alpha\left[\bar{u}_{W}-h l\right]+(1-w \alpha)\left[v \cdot 0+(1-v)\left(\bar{u}_{W}-h l\right)\right]-w K,
\end{aligned}
$$

and

$$
\begin{aligned}
U_{H}\left(w, h ; w^{e}, \alpha\right) & =\operatorname{Prob}[\theta=1] \cdot \bar{u}_{H}+\operatorname{Prob}[\theta=0] \cdot h S\left(w^{e}, \alpha\right) \\
& =(1-w \alpha) v \bar{u}_{H}+[1-(1-w \alpha) v] h k\left(\operatorname{Prob}\left[a_{W}=c \mid w^{e}, \alpha, \theta=0\right]-\operatorname{Prob}\left[a_{W}=n \mid w^{e}, \alpha, \theta=0\right]\right) .
\end{aligned}
$$

An equilibrium of this game is a pair $\left(w^{*}, h^{*}\right)$ such that (i) $w^{*}$ maximizes $U_{W}\left(\cdot, h^{*}\right)$ and (ii) $h^{*}$ maximizes $U_{H}\left(w^{*}, \cdot ; w^{*}, \alpha\right)$.

Equilibrium Characterization. $H$ 's (subjective) conditional probability of $a_{w}=c$ when $\theta=0$ is given by $\rho=\frac{w^{e} \alpha}{w^{e} \alpha+\left(1-w^{e} \alpha\right)(1-v)}$. When $\theta=0$, hence, $H$ 's (subjective) payoff is $(2 \rho-1) k$ if $a_{H}=b$ and 0 if $a_{H}=g$. That is, $a_{H}=b(h=1)$ is a best reply if and only if

$$
\rho \geq 1 / 2 \Longleftrightarrow w^{e} \alpha \geq\left(1-w^{e} \alpha\right)(1-v)
$$

Notice that when $\alpha$ is sufficiently low (i.e., $\alpha<\frac{1-v}{2-v}$ ), being a bad husband can never be a best reply (i.e., even if $w=1)$.

Next, let's consider $W$ 's best reply. As $a_{W}$ is relevant only when injectables are available, she (weakly) prefers $a_{W}=c$ if and only if $\alpha\left(\bar{u}_{W}-h l\right)+(1-\alpha)(1-v)\left(\bar{u}_{W}-h l\right)-K \geq(1-v)\left(\bar{u}_{W}-h l\right)$, which simplifies to

$$
\bar{u}_{W}-h l \geq \frac{K}{\alpha}
$$

Thus, there are two possible cases depending on $\alpha$.

- Case 1: $\alpha<\frac{1-v}{2-v}$. In this case, $h=0$ is a dominant strategy for $H$, and $w=1$ is the unique best reply of $W$. That is, $\left(w^{*}, h^{*}\right)=(1,0)$ is the unique equilibrium.

- Case 2: $\alpha \geq \frac{1-v}{2-v}$. In this case, it is easy to see that there exists no pure strategy equilibrium. The unique mixed strategy equilibrium is given by (4) and (5) with equalities, which reduce to $(w, h)=$ 


$$
\left(\frac{1-v}{\alpha(2-v)}, \frac{\bar{u}_{W}-\frac{K}{\alpha}}{l}\right)
$$

Prediction. As the scope for moral hazard increases - that is, as $\alpha$ goes up - the use of contraception decreases and shading increases. When moral hazard is limited in scope $\left(\alpha<\frac{1-v}{2-v}\right)$, increases in $\alpha$ lead to an increase in $W$ 's payoff and a decrease in $H$ 's payoff. If the scope for moral hazard is large enough $\left(\alpha>\frac{1-v}{2-v}\right)$, further increases in $\alpha$ lower both $H$ and $W$ 's payoffs.

Proof. The fact that as $\alpha$ goes up the use of contraception goes down and the quantity of shading goes up immediately follows when (i) comparing $h^{*}$ and $w^{*}$ between case $1\left(\alpha<\frac{1-v}{2-v}\right)$ and case $2\left(\alpha>\frac{1-v}{2-v}\right)$ and (ii) looking at how $\alpha$ enters $h^{*}$ and $w^{*}$ in case 2. The statements regarding the changes in payoffs can immediately be seen by substituting the pair $\left(h^{*}, w^{*}\right)$ into $(2)$ and $(3)$.

Intuition. To gain intuition for the predictions stated above it is useful to bear in mind that $H$ will shade - and thus impose a loss on $W$ - only if confident enough (suspicious enough) that $W$ used injectables. When $\alpha$ is low $\left(\alpha<\frac{1-v}{2-v}\right)$-injectables are likely stocked out $-H$ rationally infers when $\theta=0$ that the most likely reason for the lack of birth is simply bad luck (even if he understands that $W$ did attempt to gain access to injectables). In these instances, $H$ finds it optimal not to shade, even when no child is born. This, however, in turn implies that $W$ will attempt to obtain these injectables with probability one since she faces no prospect of retaliation. If we focus on this range of parameter values, we find that $W$ 's payoff is increasing in $\alpha$ while $H$ 's is decreasing. This is simply due to the fact that as $\alpha$ increases injectables are likely more available, thereby paving the way to lower fertily, which is beneficial to $W$ but detrimental to $H$.

Things differ, however, when $\alpha>\frac{1-v}{2-v}$. In these instances, the threat of $W$ actually accessing injectables is high enough that there is scope for shading. In particular, $H$ finds it optimal to shade often enough (when $\theta=0$ ) to make $W$ indifferent between attempting to obtain injectables or not. This likelihood of shading, not surprisingly, is increasing in $\alpha$, i.e., is increasing in the availability of injectables. $W$, on the other hand, reacts to this increased likelihood of shading when $\theta=0$ (due to a higher $\alpha$ ), by decreasing the probability with which she attempts to obtain injectables. The overall impact of changes in the availability of injectables is to (i) maintain fertility constant (any increase in $\alpha$ is offset by a proportionate decrease in $w$, see the formula for $w^{*}$ above) and (ii) decrease both payoffs as $W$ is facing more shading and $H$ is unfairly punishing his wife (which he dislikes).

To conclude, let us briefly comment on the predictions regarding the experiment itself. Similar to the cooperative model presented in the paper, secretly handing a voucher guaranteeing access to injectables at no cost can only make $W$ better-off and lead to a lower level of fertility. This is once again due to a revealed preference argument. $H$ having the wrong beliefs concerning $W$ 's access to injectables (he underestimates it) in the Individual group, $W$ can always guarantee herself the payoff accruing to the wifes in the Couple group simply by mimicking their behavior. If $W$ decides not to mimick their behavior, then it must follow that her 
payoff increases. As we describe in the Results and Discussion section, she did indeed increase her Injectable usage and decrease her fertility in the Individual condition compared to the Couple condition. However, 2 years after the experimental intervention, although there is no difference in violence or separation, women in couples with misaligned incentives do report a lower level of subjective well-being. Although we don't have any evidence that men found out about injectable use (and hence we cannot compare this to the long run case in the framework above), it does point to the general costs associated with increasing concealability. In the long run, the increase in the scope for hidden action comes simply from increasing access to a contraceptive that is almost perfectly concealable, in terms of being hard for the man to monitor. The mistrust resulting from this increased access, which is common knowledge in the long run, leads to lower welfare for both in the long.

\section{Sample Recruitment and External Validity}

As described in the paper, married women of childbearing age (18-40) were invited to participate in the study if they: (1) currently lived with their husband; (2) had last given birth between January 2004 and December 2006; (3) were not currently pregnant; (4) had neither been sterilized nor had a hysterectomy; (5) were not known to have health conditions for which hormonal contraceptives are contraindicated; and (6) agreed to participate in a survey and information session about family planning together with their husband. In the first stage, which took place in July and August of 2006, subjects were recruited from the roster of women who, according to clinic obstetric records, met inclusion criteria (2) and (5), and who resided at the address listed in the records. Only around 50 percent of those women could be located, largely because of false or missing addresses and high rates of mobility within the city. ${ }^{3}$ Therefore, women were also invited to participate in the study if they resided at the house number listed for the intended respondent and met all six inclusion criteria. ${ }^{4}$ If more than one eligible woman resided at a sampled address, the one whose first name came first in alphabetical order was invited to participate.

To expand the sample, from August 2006 to April 2007, women were recruited by randomly sampling house numbers in the neighborhoods that comprise the catchment area of the clinic. ${ }^{5}$ Women residing at sampled house numbers were invited to participate if they met all six inclusion criteria.

In order to provide wait-free appointments with guaranteed access, we hired a dedicated nurse for the study and purchased sucient stocks of injectable contraceptives (Depo-Provera) and contraceptive implants (Jadelle) to treat all women in the sample for at least one year. ${ }^{6}$ These stocks and the nurse were reserved

\footnotetext{
${ }^{3}$ Clinic staff reported that false addresses were often given by women who resided outside the catchment area in order to obtain services at Chipata clinic, which is larger and much better equipped than other clinics in Lusaka. To the extent this is true, women who were found are a representative sample from the catchment area.

${ }^{4}$ Of the women recruited in the first stage, 74 percent were taken from obstetrics records and 26 percent were alternates residing at the addresses listed in the records.

${ }^{5}$ The catchment area is approximately 8 square kilometers and densely populated, encompassing an estimated 107,107 people. Women who had already been included in the sample from the process above were excluded from this random sampling expansion process.

${ }^{6}$ Sufficient stocks of condoms, pills, and IUDs were already available at the clinic. To keep waiting lines short we spaced the
} 
exclusively for women in our study. Hence, the voucher signicantly reduced barriers to accessing all forms of contraception, but in particular long-acting methods. The voucher, a copy of which appears in Section 4, was valid for one month from the day it was issued. ${ }^{7}$ To ensure that vouchers were not used by individuals outside of our sample, the wife's name and national ID numbers were written on the voucher by enumerators, and women were instructed to bring their ID cards to the clinic at the time of the visit for the nurse to verify. Responses to the debrieng survey were also used to verify the identities of women using the voucher.

As described in the paper, the experiment consisted of a baseline survey in the first visit administered solely to the wife, during which an appointment was made for a second visit with both the wife and husband. Treatment (Individual versus Couple) was then randomly assigned. ${ }^{8}$ Among the 1031 women eligible for inclusion in the experiment, 749 participated, including 371 assigned to the Couple treatment condition and 378 assigned to the Individual condition. Figure 1 shows the breakdown of reasons for non-participation. Non-participation overwhelmingly reflected resource constraints on the part of the investigators and a strict timeline for completion of the study, both of which caused us to halt recruitment efforts before all households could be reached for a second visit.

In terms of external validity, it is worth keeping in mind that some amount of the non-participation discussed above may reflect subjects' tacit unwillingness to participate in the study. However, the direction of bias due to this type of sample selection is unclear. Wives with husbands who are most unwilling to participate in a family planning survey may be the most likely to hide contraception when given the opportunity, in which case our experimental results underestimate the average effect of the intervention on the population of eligible women. Alternatively, attrition may be driven by women with no interest in family planning who would be little influenced by treatment assignment, in which case our estimates overstate the average population effect.

Comparing observables in our sample with those of married women in Lusaka from the 2007 ZDHS sheds some light on the representativeness of our sample (Table A.2). In many respects, such as education and desired fertility, our sample is very similar to the random sample from the ZDHS. However, the means indicate that our sample is composed of a disproportionate number of couples with discordant fertility preferences and relatively frequent intercourse. These differences suggest that our experimental sample is at greater risk of an unwanted birth than the average woman in urban Zambia. Furthermore, women in our sample also have significantly more experience using modern contraceptives than the average woman in urban Zambia, likely due to their proximity to the clinic. Both differences are consistent with the case in which the most important source of selection into our study is interest in modern family planning methods. Although this suggests that our expected treatment effect may be larger than what we would anticipate were the experiment conducted on a random sample of women from the same population (although not definitively), we are arguably still capturing the estimate of interest for policy purposes by implicitly restricting the sample to women with a

\footnotetext{
intervention over 4 months, distributing approximately 50 vouchers per week.

7 To minimize confusion over the over period, the expiration date was written clearly on each voucher by the CHW on the day of the second visit.

${ }^{8}$ Our choice to balance treatment assignment on baseline characteristics prevented us from randomizing earlier.
} 
demand for family planning services and relatively good access to public services since this is the group that would be influenced by policy measure such as increasing access to injectable contraceptives.

\section{Script 1: Condom and Family Planning Information}

Information on STDs and Condoms

- Did you know that 1 out of 5 Zambians over the age of 15 is HIV positive?

- If used correctly and consistently, condoms will protect you from getting sexually transmitted diseases and HIV, the virus that causes AIDS. There is no known cure for AIDS.

- Condoms will keep you among the 4 out of 5 who can still avoid HIV

- Facts about Sexually Transmitted Diseases

- Anyone can become infected through sexual intercourse with an infected person.

- Changing sexual partners adds to the risk of becoming infected.

- Sometimes, early in the infection, there may be no symptoms, or symptoms may be easily confused with other illnesses.

- Sexually transmitted diseases can cause:

* Tubal pregnancies, sometimes fatal to the mother and always fatal to the unborn child

* Death or severe damage to a baby born to an infected woman

* Sterility (loss of ability to get pregnant)

* Cancer of the cervix in women

* Damage to other parts of the body, including the heart, kidneys, and brain

* Death to infected individuals

* See a doctor if you have any of these symptoms of STDs:

* Discharge from the vagina, penis, and/or rectum

* Pain or burning during urination and/or intercourse

* Pain in the abdomen (women), testicles (men), and buttocks and legs (both)

* Blisters, open sores, warts, rash, and/or swelling in the genital area, sex organs, and/or mouth

* Flu-like symptoms, including fever, headache, aching muscles, and/or swollen glands

- The surest way to avoid sexually transmitted diseases is to not have sex altogether (abstinence). Another way is to limit sex to one partner who also limits his or her sex in the same way (monogamy). Condoms are not 100 percent safe, but if used properly, will reduce the risk of sexually transmitted diseases, including AIDS. Protecting yourself against the AIDS virus is of special concern because this disease is fatal and has no cure. 
- Condoms will help protect you from having an un-planned pregnancy which could ruin your plans and overburden you with responsibilities you are not ready for. Condoms are used for both birth control and reducing the risk of disease. That is why some people think that other forms of birth control - such as the IUD, injectable, or pill - will protect them against diseases, too. But that is not true. So if you use any other form of birth control, you still need a condom in addition to reduce the risk of getting sexually transmitted diseases. This is called dual protection, and it is very important to practice it.

- A condom is especially important when an uninfected pregnant woman has sex, because it can also help protect her and her unborn child from a sexually transmitted disease.

- A condom prevents the transmission of disease. It acts as a barrier or wall to keep blood, or semen, or vaginal fluids from passing from one person to the other during intercourse.

- These fluids can harbor germs such as HIV (the AIDS virus). If no condom is used, the germs can pass from the infected partner to the uninfected partner.

- What is the correct way of using condoms?

- First ensure that you have them available so that you are ready when you need one.

- Always check the expiry date of the condoms

- Keep your condoms away from heat and direct sunlight.

- Use a new condom for each act of sex.

- Deciding to use condoms is an important choice you make to protect yourself, your partner and your loved ones.

- Do not be embarrassed about protecting yourself and your loved ones. Is it not more embarrassing to end up with an unplanned pregnancy, or an STD which could be HIV when you can avoid all that? Think about the future plans you have made for yourself and for them. Make the right choice of condoms and continue with your plans.

- Remember you are in-charge of your life and the decisions you make. Be responsible to yourself and use condoms!

General Information on Family Planning

A. Definition of family planning

1. Family planning is a decision about:

- How many children to have, when to start having them, how long to wait in between each one (spacing), and when they will stop

B. Benefits of family planning

1. Benefits to children: 
- Better health, more food and other resources available, greater opportunity for emotional support from parents, better opportunity for education

2. Benefits to women:

- Better health and possibly protection from certain diseases, freedom to decide when to have children, less physical and emotional strain, no need for unsafe abortions, improved quality of life

3. Benefits to men:

- Protection from STDs/HIV with some methods (barrier methods), less emotional and financial strain, greater care for each child, improved quality of life

C. Methods of family planning

1. Many different methods out there; some require nurse and some do not:

- Barrier methods such as male and female condoms

- IUDs (implants)

- Surgical sterilization

- Hormonal methods such as pills, injectables and implants

- Natural methods such as withdrawal, the rhythm method and abstinence

D. Importance of condoms

1. ONLY CONDOMS PROVIDE PROTECTION AGAINST STDs and HIV/AIDS.

2. [Offer woman pack of 3 condoms]. Even if you are married, and even if you are using another method of birth control, it may still be appropriate to use condoms as dual protection against both pregnancy and HIV/AIDS.

3. Please keep these condoms provided by the clinic

E. Chipata clinic services

1. Nurse at Chipata Clinic can help you to choose and properly use the method that is best for you

2. For more information, visit the family planning nurse, Grace Daka

3. Clinic is open for family planning services from 13 hours to 17 hours, Mon - Saturday

4. Do you know how to get there? 
Additional Information About Family Planning

1. Now I'll tell you about two family planning options that many people don't know about

2. But there are other options, so take time to explore all of the choices to figure out what is best for you

A. Description of injectables (Depo-Provera)

1. Depo Provera is an injection given in arm or rear that prevents pregnancy for 3 months

2. Injection contains same type of medicine as EC and some pills - synthetic progesterone hormone

3. It prevents pregnancy by stopping release of eggs. It also causes cervical mucus to thicken, making it harder for sperm to enter or survive in uterus. These changes prevent fertilization and thus pregnancy

B. Benefits of using

1. Injectables are very reliable:

- Of 1,000 women who use it correctly, only 3 become pregnant during first year of use

- After first injection, protection from pregnancy is immediate if you take shot during first 5 days of your period. Otherwise, it begins to work after 1 week (so use backup method of contraception)

- Protection lasts for 12 weeks

2. Injectables are reversible:

- Women who want to become pregnant at any time can stop using injectables

- For many women, fertility returns immediately, but for some it may take over 1 year

3. Injectables very private form of birth control

- It cannot be seen on body and requires no home supplies

- You do not have to keep any pills at home, which your husband may find

- There is nothing for you or your husband to put in place before intercourse

4. Injectables very convenient - only requires 1 clinic appointment every 3 months.

- However, very important to follow the date given to return to the clinic

- If you are late returning to get your shot you will risk getting pregnant! 
5. Injectables can also cause changes to menstrual cycle, including:

- Less menstrual cramping and pain, fewer periods, and less chance of anemia

- Irregular or no bleeding at all. Many women stop having periods after one year.

- DON'T WORRY: THIS IS NOT UNHEALTHY!!! This in no way prevents future pregnancy or harms a woman's reproductive capacity. In fact, many women find this to be a welcome convenience!

6. For most women Depo Provera is safe and reliable method of postponing pregnancy

C. I would also like to inform you that Jadelle implants have recently become available at Chipata Clinic.

- Jadelle is for women who are looking for a reliable, reversible long-term method of birth control

- Consist of two small silicone rods containing synthetic hormones

- Rods are inserted under the skin in the arm

- Once inserted, implants very effectively prevent pregnancies for up to five years - you don't have to do anything after the initial insertion for them to work

- The rods are usually barely visible - because the incision from insertion is very small, most women do not have a visible scar.

- The rods can be removed.

- Once removed, contraceptive effects disappear within a few days.

- Need to be inserted and removed by trained health care personnel

- Because the hormone in Jadelle is the same as the hormone in injectables, the contraindications and side effects are similar

- Discuss carefully with the nurse in order to determine whether Jadelle is the right option for you

Before you consider either IC or Jadelle, there are three important things to remember:

D. Neither Jadelle nor injectable contraceptives protect against STDs including HIV/AIDS

1. To protect yourself, you should also use a condom - this is called dual protection

E. Injectables and Jadelle are not safe for women with:

- Past heart attack or stroke, blood clots in the legs or lungs

- Cancer or epilepsy

- High blood pressure

- Heart, kidney, or liver disease, such as hepatitis 
- Are or might be pregnant, want to become pregnant immediately

- Unexplained bleeding from the vagina

- History of severe depression

F. If you had bad experiences with hormonal contraceptives (pills, injectables, or implants) in the past, consult the family planning nurse before trying a hormonal method again as you may have a similar experience if you try them again.

G. Mild side effects are likely with both methods

1. Most common are temporary and not dangerous, but can be uncomfortable, including:

- Nausea and/or vomiting

- Breast tenderness, irregular bleeding

- Headache or dizziness

2. Other side effects of injectables only can include:

- Nervousness, mood changes

- Bloating, hot flashes, a decreased interest in sex, acne, hair loss, and back ache

- After last injection, it can take over 6 months for side effects to completely go away

3. More serious problems with injectables are very rare but can include:

- Allergic reactions

- Decrease in bone density, which can lead to osteoporosis (weak bones) when you are older

4. If you use either method, you should go to the clinic immediately if you have:

- A new lump in your breast

- Major depression

- Severe pain in the stomach or abdomen

- Unusually heavy or prolonged vaginal bleeding

- Yellowing of skin or eyes

H. Any questions about when and how to use either method, or how these methods work? If you have more questions, you can ask them of the nurse at the family planning clinic and she will help you to choose the method that is best for you. 


\section{Voucher}

Individuals
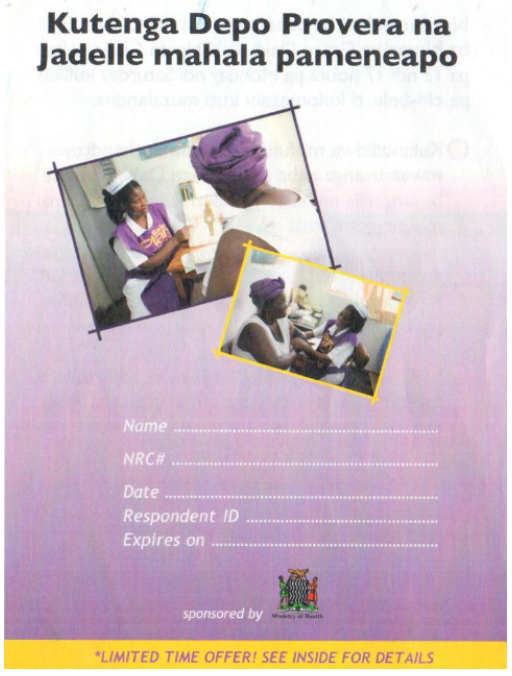

Couples

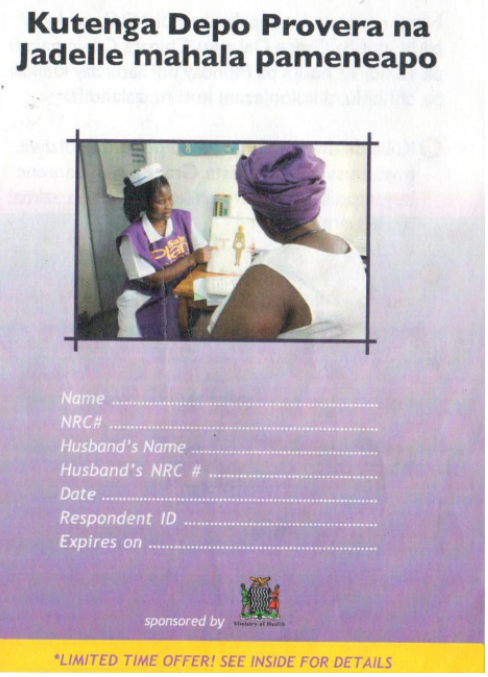

English Translation of Voucher: If you bring this voucher with your NRC card to the Nurse Grace Daka at Chipata Clinic between $14 \mathrm{~h}$ and $17 \mathrm{~h}$ on Monday and Saturday, we guarantee that you will receive:

- First class, personalized service, by Grace Daka, your own dedicated family planning nurse.

- You will not wait for more than an hour, and receive a free gift if you wait more than an hour.

- A family planning method Jadelle or an injectable Depo-Provera for one year will be given to you for a year if Nurse Grace Daka finds it suitable for you.

\section{Husband Survey and Voucher Script and Protocol}

STEP 1 (CHW) Hello, my name is and I am representing Chipata Clinic. We are going today to randomly selected households in your area, in order to conduct a survey about families and family planning.

STEP 2 (CHW) Are both you and your husband here? Yes/ Yes let me go get him. (Go to STEP 4 ) No he is not here. (Go to STEP 3)

STEP 3 (CHW) If no, do you know when you both will next be at home? [Schedule directly with husband if possible.] 
Month Day Time

STEP 4 (Enumerator)

[Once you have found the correct respondent]

I am a representative of Chipata Clinic. We would like you to participate in our study about family planning. We are administering a survey about women and men's attitudes towards having children, raising children and family planning.

The entire session will take approximately fifteen minutes. Since we really value how you can help us to learn about women and their decisions about children, you will receive a gift of for spending your time with us.

If you choose to participate, all of the session is voluntary, and you may choose not to answer any of the questions I ask if you prefer not to. Also, every piece of information you give will be kept strictly confidential. Your name will be removed from any of the information that you give as soon as it is entered into the computer, and only staff members at the clinic and members of the research team will have access to the information.

\section{STEP 5 (Enumerator and CHW)}

First we would like to talk to the husband in private. Is there a quiet place where we can conduct the survey in private? Can we go inside your house to conduct the survey? [If there is no private setting, arrange to return at a later time, preferably later on the same day.]

If there is no place to conduct a private interview, write the date and time of the appointment below:

Month Day Time

\section{STEP 6a (Enumerator)}

[Go to private setting and administer husband survey. Both CHW and enumerator should be present during survey. Note whether there is a voucher attached to the survey. If there is a voucher, go to step $6 \mathrm{~b}$. If there is no voucher, go to step 7a. Give husband gift of either 10,000 talk time or kwacha when survey is completed.] 


\section{STEP 6b [VOUCHER ATTACHED TO HUSBAND SURVEY] (Enumerator)}

[If there is a voucher attached to the survey, then invite woman into the house]

Your household has also been selected by lottery to be eligible to receive special services from Chipata Clinic's family planning clinic. This voucher entitles you to first-rate care from your own dedicated family planning nurse. It also will enable you to access methods of family planning that are extremely effective, private and easy to use. These methods do not require you to do something every day, or to do something every time you have sex in order to be effective. These methods are not available to all people who come into Chipata Clinic because there are more people who want to use these methods than the clinic is able to serve.

This voucher is especially for you and only you, and it cannot be used by anyone else. In order to ensure that this is only for you, we will write both of your names and NRC numbers on the card.

STEP 7a [NO VOUCHER ATTACHED TO WIFE SURVEY] (Enumerator)

[Go to private setting and administer wife survey. Both CHW and enumerator should be present during survey. Go to step 8.]

\section{STEP 7b [VOUCHER ATTACHED TO WIFE SURVEY] (Enumerator)}

[If there is a voucher attached to the survey, then give to woman in private, before completing survey. Make sure no one else is around when she receives the voucher so that her privacy is completely ensured]

You have also been selected by lottery to be eligible to receive special services from Chipata Clinic's family planning clinic. This voucher entitles you to first-rate care from your own dedicated family planning nurse. It also will enable you to access methods of family planning that are extremely effective, private and easy to use. These methods do not require you to do something every day, or to do something every time you have sex in order to be effective. These methods are not available to all people who come into Chipata Clinic because there are more people who want to use these methods than the clinic is able to serve. This gift is for you, the woman, and it is your choice to share this with your husband or to keep it for yourself. If you like, we can keep this card at the clinic for you.

This voucher is especially for you and only you, and it cannot be used by anyone else. In order to ensure that this is only for you, we will write your name and NRC number on the card.

[Administer wife survey part II.]

STEP 8 (Enumerator)

Thank woman for her time, give her chitenge or 10,000 kwacha and say goodbye. 
Voucher Talking Points, as Emphasized in Field Worker Training

(These points must be emphasized to women or the couple, depending on the treatment.)

For Couples Women:

1. They are one of the lucky couples chosen to receive a special, limited-time offer of guaranteed quick, easy access to family planning methods like Jadelle and Depo-Provera.

2. The voucher guarantees immediate access to Depo Provera and Jadelle provided these methods are medically appropriate for them. This voucher will also give them access to other family planning methods available at Chipata Clinic.

3. They should ask for our study's dedicated family planning nurse Grace Daka. She is available at Chipata Clinic Monday through Saturday from 13-17 hours until the expiration date written on the voucher.

4. This voucher guarantees a wait time of less than an hour.

5. They will be given a free surprise gift if they are one of the first 50 women.

6. They will not be seen without a voucher.

7. The voucher is only for them, not for anyone else. No one else can use this voucher.

For Individual Women:

1. This voucher guarantees quick, easy, private access to Depo-Provera and Jadelle. The husband does not know about this voucher, and no one will require any husband involvement. It is completely up to the woman whether or not to tell her husband about this voucher.

2. They are one of the lucky women chosen to receive a special, limited-time offer of guaranteed quick, easy access to family planning methods like Jadelle and Depo-Provera provided these methods are medically appropriate for them.

3. This voucher will also give them access to other family planning methods available at Chipata Clinic.

4. They should ask for our dedicated family planning nurse Grace Daka. She is available at Chipata Clinic Monday through Saturday from 13-17 hours until the expiration date written on the voucher.

5. This voucher guarantees a wait time of less than an hour. 
6. They will be given a free surprise gift if they visit the clinic if they are one of the first fifty women.

7. They will not be seen without a voucher.

8. The voucher is only for them, not for anyone else. No one else can use this voucher. 


\section{References}

Ashraf, Nava, Erica Field, and Marric Buessing. 2012. "Access to Contraception can Imrove Mental Health Indicators: Experimental Evidence from Zambia." Working Paper.

Fehr, Ernst, Oliver Hart, and Christian Zehnder. 2011. "Contracts as Reference Points - Experimental Evidence." American Economic Review, 101(2): 493-525.

Hart, Oliver, and John Moore. 2008. "Contracts as Reference Points." The Quarterly Journal of Economics, 123(1): 1-48. 
Figure A.1: Gender gap in mean ideal number of children

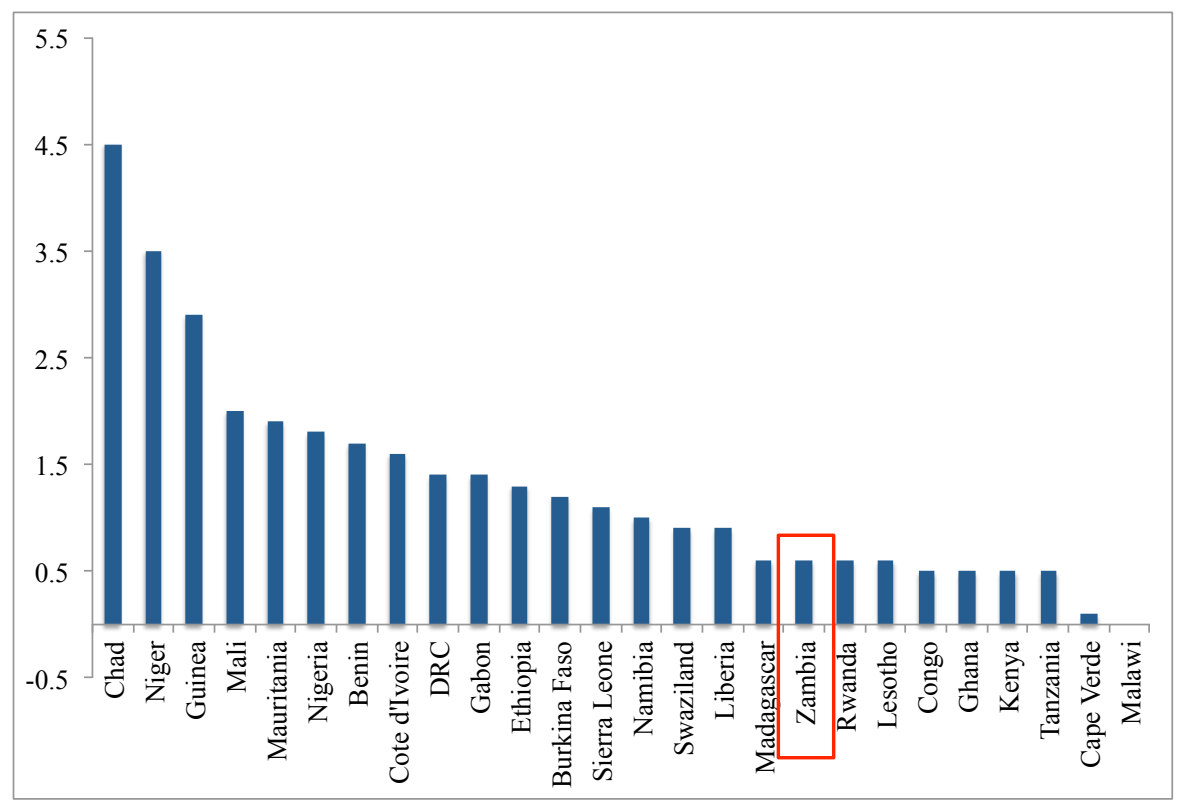

Source: Westoff (2010). 
Table A.1: Summary Statistics for Recruited Sample

\begin{tabular}{|c|c|c|c|c|c|c|c|}
\hline & \multicolumn{3}{|c|}{ Individual Treatment } & \multicolumn{3}{|c|}{ Couple Treatment } & \multirow[b]{2}{*}{ P-Value } \\
\hline & Mean & Standard Error & $\mathrm{N}$ & Mean & Standard Error & $\mathrm{N}$ & \\
\hline \multicolumn{8}{|l|}{ Panel A } \\
\hline Highest schooling attained & 6.672 & 0.190 & 472 & 6.524 & 0.135 & 460 & 0.437 \\
\hline Husband's highest schooling attained (reported by wife) & 9.623 & 0.176 & 475 & 9.411 & 0.125 & 455 & 0.227 \\
\hline Ideal number of children & 3.939 & 0.0979 & 528 & 3.964 & 0.0700 & 503 & 0.800 \\
\hline Age & 27.47 & 0.380 & 528 & 27.51 & 0.272 & 499 & 0.918 \\
\hline Husband's age (reported by wife) & 34.31 & 0.456 & 461 & 34.26 & 0.326 & 442 & 0.909 \\
\hline Husband's ideal number of children (reported by wife) & 4.233 & 0.123 & 490 & 4.244 & 0.0879 & 464 & 0.929 \\
\hline Has ever used a modern contraceptive method & 0.886 & 0.0206 & 528 & 0.865 & 0.0147 & 503 & 0.295 \\
\hline Wife has monthly income & 0.347 & 0.0301 & 528 & 0.394 & 0.0215 & 503 & 0.118 \\
\hline Wife knows when she is most fertile & 0.158 & 0.0227 & 482 & 0.124 & 0.0162 & 460 & 0.137 \\
\hline Wife wants to become pregnant in following 2 years & 0.252 & 0.0273 & 528 & 0.264 & 0.0195 & 503 & 0.646 \\
\hline Age wife married & 19.42 & 0.262 & 521 & 19.15 & 0.188 & 497 & 0.301 \\
\hline Catholic & 0.231 & 0.0263 & 528 & 0.231 & 0.0188 & 503 & 0.987 \\
\hline \multicolumn{8}{|l|}{ Comparison of happiness with other women in region } \\
\hline \multicolumn{8}{|l|}{ Comparison of health with other women in region } \\
\hline$(1=$ very poor, $5=$ excellent $)$ & 3.619 & 0.0477 & 528 & 3.651 & 0.0342 & 502 & 0.502 \\
\hline Number of years respondent lived in Lusaka & 18.24 & 0.674 & 528 & 18.06 & 0.483 & 501 & 0.790 \\
\hline Couple has electricity & 0.384 & 0.0304 & 528 & 0.388 & 0.0217 & 503 & 0.916 \\
\hline Formally married & 0.865 & 0.0209 & 527 & 0.877 & 0.0150 & 503 & 0.584 \\
\hline Number of days in past 7 days couple has sex & 2.019 & 0.102 & 523 & 2.002 & 0.0731 & 501 & 0.867 \\
\hline Number of days in past month couple has sex & 7.929 & 0.337 & 523 & 7.891 & 0.242 & 496 & 0.910 \\
\hline Number of children husband has with other women & 0.308 & 0.0291 & 510 & 0.300 & 0.0207 & 494 & 0.777 \\
\hline \multicolumn{8}{|l|}{ Frequency at which couple has talked about contraception in last } \\
\hline year & 1.723 & 0.0671 & 528 & 1.684 & 0.0480 & 503 & 0.555 \\
\hline Couple has ever disagreed on number of children & 0.136 & 0.0214 & 528 & 0.137 & 0.0153 & 503 & 0.970 \\
\hline Couple has ever disagreed on contraception use & 0.120 & 0.0204 & 527 & 0.125 & 0.0146 & 503 & 0.780 \\
\hline Have used contraceptive method without husband's knowledge & 0.160 & 0.0227 & 526 & 0.152 & 0.0162 & 501 & 0.724 \\
\hline Husband drinks at least 2 to 3 times a week & 0.432 & 0.0309 & 528 & 0.423 & 0.0221 & 503 & 0.787 \\
\hline Husband has ever threatened physical violence & 0.540 & 0.0310 & 528 & 0.559 & 0.0222 & 503 & 0.543 \\
\hline Wife ever pressured to have sex & 0.546 & 0.0311 & 527 & 0.543 & 0.0222 & 503 & 0.904 \\
\hline Husband does budgeting & 0.140 & 0.0218 & 527 & 0.143 & 0.0156 & 502 & 0.890 \\
\hline Husband decides major purchases & 0.650 & 0.0298 & 525 & 0.648 & 0.0213 & 503 & 0.962 \\
\hline Joint F Statistic & & & & & & & 11.90 \\
\hline \multirow[t]{3}{*}{ P-value } & & & & & & & 0.998 \\
\hline & \multicolumn{3}{|c|}{ Individual Treatment } & \multicolumn{3}{|c|}{ Couple Treatment } & \\
\hline & Mean & Standard Error & $\mathrm{N}$ & Mean & Standard Error & $\mathrm{N}$ & $\overline{\text { P-Value }}$ \\
\hline \multicolumn{8}{|l|}{ Panel B } \\
\hline Using any method at baseline & 0.844 & 0.0223 & 527 & 0.855 & 0.0160 & 498 & 0.622 \\
\hline Number of living children & 2.922 & 0.112 & 527 & 2.903 & 0.0803 & 497 & 0.867 \\
\hline Using injectable at baseline & 0.194 & 0.0253 & 527 & 0.219 & 0.0181 & 498 & 0.317 \\
\hline Using pill at baseline & 0.292 & 0.0283 & 527 & 0.279 & 0.0203 & 498 & 0.643 \\
\hline Using a hormonal contraceptive at baseline & 0.488 & 0.0313 & 527 & 0.506 & 0.0224 & 498 & 0.557 \\
\hline Has ever used an injectable contraceptive method & 0.405 & 0.0307 & 528 & 0.416 & 0.0220 & 503 & 0.739 \\
\hline Months since last birth (at recruitment) & 15.46 & 0.377 & 527 & 15.30 & 0.271 & 498 & 0.653 \\
\hline Husband's age (reported by husband) & 33.89 & 0.561 & 380 & 34.21 & 0.398 & 375 & 0.561 \\
\hline Husband's highest schooling attained (reported by husband) & 8.814 & 0.211 & 382 & 8.699 & 0.150 & 375 & 0.585 \\
\hline Husband's ideal number of children (reported by husband) & 4.204 & 0.148 & 378 & 4.433 & 0.105 & 372 & 0.122 \\
\hline Husband's average monthly income (1,000 USD) (reported by husband) & 0.130 & 0.0158 & 382 & 0.153 & 0.0113 & 375 & 0.159 \\
\hline Wife earned money in previous month & 0.398 & 0.0309 & 525 & 0.446 & 0.0221 & 498 & 0.123 \\
\hline Husband works $40+$ hours & 0.588 & 0.0317 & 505 & 0.554 & 0.0228 & 473 & 0.280 \\
\hline Wife ever pressured violently to have sex & 0.135 & 0.0218 & 524 & 0.148 & 0.0156 & 501 & 0.575 \\
\hline Husband decides savings & 0.617 & 0.0303 & 528 & 0.628 & 0.0217 & 500 & 0.727 \\
\hline Husband holds the money & 0.159 & 0.0231 & 521 & 0.166 & 0.0165 & 499 & 0.762 \\
\hline
\end{tabular}


Table A.2: Final Experimental Sample vs. DHS Summary Statistics

\begin{tabular}{|c|c|c|c|c|c|c|c|c|c|}
\hline & \multicolumn{3}{|c|}{$\begin{array}{l}\text { Final Experimental } \\
\text { Sample }\end{array}$} & \multicolumn{3}{|c|}{$\begin{array}{c}\text { DHS } 2007 \\
\text { All Women Ages } 15-49 \\
\text { Urban Locations }\end{array}$} & \multicolumn{3}{|c|}{$\begin{array}{c}\text { DHS } 2007 \\
\text { All Women Ages } 15-49 \\
\text { All Locations }\end{array}$} \\
\hline & Mean & $\begin{array}{l}\text { Standard } \\
\text { Deviation }\end{array}$ & $\mathrm{N}$ & Mean & $\begin{array}{l}\text { Standard } \\
\text { Deviation }\end{array}$ & $\mathrm{N}$ & Mean & $\begin{array}{l}\text { Standard } \\
\text { Deviation }\end{array}$ & $\mathrm{N}$ \\
\hline \multicolumn{10}{|l|}{ Variables Used to Balance Sample } \\
\hline Age & 27.61 & 6.22 & 746 & 31.20 & 0.40 & 787 & 30.91 & 0.13 & 5,420 \\
\hline Highest schooling attained & 6.58 & 2.93 & 678 & 7.50 & 0.36 & 787 & 5.95 & 0.13 & 5,420 \\
\hline Number of living children & 2.97 & 1.80 & 743 & 2.96 & 0.09 & 787 & 3.40 & 0.04 & 5,420 \\
\hline Ideal number of children & 3.96 & 1.57 & 749 & 4.28 & 0.09 & 771 & 4.98 & 0.05 & 5,068 \\
\hline Difference in husband's ideal and wife's ideal number of children (reported by wife) & 0.29 & 1.32 & 705 & & & & & & \\
\hline Using injectable at baseline & 0.24 & 0.43 & 749 & 0.11 & 0.02 & 787 & 0.08 & 0.01 & 5,420 \\
\hline Using pill at baseline & 0.31 & 0.46 & 749 & 0.13 & 0.02 & 787 & 0.10 & 0.00 & 5,420 \\
\hline \multicolumn{10}{|l|}{ Other Observable Characteristics } \\
\hline Husband's age (reported by wife) & 34.48 & 7.05 & 666 & 37.25 & 0.66 & 569 & 37.44 & 0.19 & 4,142 \\
\hline Husband's age (reported by husband) & 34.02 & 7.70 & 747 & & & & & & \\
\hline Husband's highest schooling attained (reported by wife) & 9.46 & 2.67 & 680 & 12.58 & 0.85 & 726 & 10.39 & 0.29 & 4,985 \\
\hline Husband's highest schooling attained (reported by husband) & 8.76 & 2.91 & 749 & & & & & & \\
\hline Husband's ideal number of children (reported by wife) & 4.23 & 1.88 & 705 & & & & & & \\
\hline Husband's ideal number of children (reported by husband) & 4.30 & 2.02 & 742 & & & & & & \\
\hline Using any modern contraceptive method at baseline & 0.55 & 0.50 & 749 & 0.36 & 0.02 & 787 & 0.31 & 0.01 & 5,420 \\
\hline Have ever used a modern contraceptive method & 0.83 & 0.37 & 749 & 0.81 & 0.02 & 787 & 0.69 & 0.01 & 5,420 \\
\hline Average wealth quintile (1=poorest) & & & & 4.43 & 0.09 & 787 & 3.04 & 0.07 & 5,420 \\
\hline Average monthly household income (1,000 USD) & 0.03 & 0.07 & 749 & & & & & & \\
\hline Husband's average monthly income (1,000 USD) (reported by husband) & 0.14 & 0.22 & 749 & & & & & & \\
\hline Wife knows when she is most fertile & 0.12 & 0.33 & 685 & & & & & & \\
\hline Wife would like to have a child in following 2 years & 0.27 & 0.44 & 749 & 0.15 & & 502 & 0.13 & & 3751 \\
\hline Formally married & 0.88 & 0.32 & 749 & & & & & & \\
\hline \multicolumn{10}{|l|}{ Intimacy and Violence Measures } \\
\hline Difference in husband's and wife's income & 0.30 & 0.67 & 743 & & & & & & \\
\hline Difference in husband's and wife's age & 6.47 & 3.95 & 666 & 6.12 & 0.26 & 569 & 6.35 & 0.08 & 4,142 \\
\hline Difference in husband's and wife's education & 2.81 & 2.94 & 613 & 5.19 & 0.70 & 726 & 4.59 & 0.27 & 4,985 \\
\hline Difference in wife's perception of husband's ideal and husband's actual ideal number of children & -0.04 & 1.89 & 700 & & & & & & \\
\hline Husband wants more children & 0.28 & 0.45 & 705 & 0.16 & & 558 & 0.23 & & 4,077 \\
\hline Husband wants same number of children & 0.59 & 0.49 & 705 & 0.48 & & 558 & 0.36 & & 4,077 \\
\hline Husband wants less children & 0.13 & 0.34 & 705 & 0.09 & & 558 & 0.06 & & 4,077 \\
\hline Number of days in past 7 days couple had sex & 2.07 & 1.65 & 742 & 0.47 & 0.02 & 787 & 0.47 & 0.01 & 5,412 \\
\hline Number of children husband has with other women & 0.57 & 1.16 & 731 & & & & & & \\
\hline Frequency at which couple has talked about contraception in last year & 1.74 & 1.05 & 749 & & & & & & \\
\hline Couple has ever disagreed on number of children & 0.13 & 0.34 & 749 & & & & & & \\
\hline Couple has ever disagreed on contraception use & 0.11 & 0.31 & 749 & & & & & & \\
\hline Have used contraceptive method without husband's knowledge & 0.14 & 0.35 & 747 & & & & & & \\
\hline Husband has ever threatened physical violence & 0.54 & 0.50 & 749 & & & & & & \\
\hline Husband has ever been physically violent conditional on having threatened violence & 0.67 & 0.47 & 402 & & & & & & \\
\hline Wife ever pressured to have sex & 0.51 & 0.50 & 749 & & & & & & \\
\hline Wife ever pressured violently to have sex & 0.14 & 0.35 & 745 & & & & & & \\
\hline \multicolumn{10}{|l|}{ Financial Decision Making Measures } \\
\hline Husband decides savings & 0.62 & 0.49 & 746 & & & & & & \\
\hline Husband holds the money & 0.17 & 0.37 & 740 & & & & & & \\
\hline Husband does budgeting & 0.15 & 0.36 & 748 & & & & & & \\
\hline Husband decides major purchases & 0.65 & 0.48 & 748 & 0.34 & 0.03 & 571 & 0.44 & 0.01 & 4,160 \\
\hline
\end{tabular}

Notes:

[1] Final experimental sample includes all households that received a voucher ("Final sample").

[2] Variables 26 through 28 were asked differently across the two surveys. The DHS asked directly "Does your husband want more, fewer, or the same number of kids as you do", whereas in our data these variables were constructed from separate survey questions regarding the wife's ideal number of children and her perception of

her husband's ideal number of children. The higher reporting of husbands who want the same number of children in the latter study could also be a result

of the ordering of the questions, since the wife was asked what she thinks her husband's ideal number of children is soon after she was asked about her ideal number.

[3] The variable "Wife would like to have a child in 2 years", was also defined differently across the two surveys. In our survey data,

a respondent was said to want a child in the next two years if she either answered "within two years" to the question "If it were completely up to you,

would you like to have another child within the next two years, after two years or not at all?" or if she answered 0 to 24 months when asked

"If it were completely up to you, how long would you like to wait until the birth of another child?", whereas the DHS survey only contains the former question. 
Table A.3: Summary Statistics for Responder Sample

\begin{tabular}{|c|c|c|c|c|c|c|c|}
\hline & \multicolumn{3}{|c|}{ Individual Treatment } & \multicolumn{3}{|c|}{ Couple Treatment } & \multirow[b]{2}{*}{ P-Value } \\
\hline & Mean & Standard Error & $\overline{\mathrm{N}}$ & Mean & Standard Error & $\mathrm{N}$ & \\
\hline \multicolumn{8}{|l|}{ Panel A } \\
\hline Highest schooling attained & 7.048 & 0.434 & 84 & 6.957 & 0.322 & 69 & 0.834 \\
\hline Husband's highest schooling attained (reported by wife) & 9.683 & 0.430 & 82 & 9.250 & 0.318 & 68 & 0.316 \\
\hline Ideal number of children & 3.400 & 0.229 & 95 & 3.405 & 0.172 & 74 & 0.981 \\
\hline Age & 27.11 & 0.911 & 95 & 27.43 & 0.683 & 74 & 0.720 \\
\hline Husband's age (reported by wife) & 34.16 & 1.173 & 88 & 33.78 & 0.878 & 69 & 0.749 \\
\hline Husband's ideal number of children (reported by wife) & 4.642 & 0.331 & 95 & 5.068 & 0.248 & 74 & 0.200 \\
\hline Has ever used a modern contraceptive method & 0.884 & 0.0514 & 95 & 0.865 & 0.0386 & 74 & 0.707 \\
\hline Wife has monthly income & 0.263 & 0.0720 & 95 & 0.392 & 0.0540 & 74 & 0.0758 \\
\hline Wife knows when she is most fertile & 0.131 & 0.0538 & 84 & 0.106 & 0.0402 & 66 & 0.644 \\
\hline Wife wants to become pregnant in following 2 years & 0 & 0 & 95 & 0 & 0 & 74 & . \\
\hline Age wife married & 19.96 & 0.705 & 93 & 18.89 & 0.528 & 73 & 0.132 \\
\hline Catholic & 0.253 & 0.0684 & 95 & 0.270 & 0.0513 & 74 & 0.797 \\
\hline \multicolumn{8}{|l|}{ Comparison of happiness with other women in region } \\
\hline \multicolumn{8}{|l|}{ Comparison of health with other women in region } \\
\hline$(1=$ very poor, $5=$ excellent $)$ & 3.621 & 0.117 & 95 & 3.703 & 0.0881 & 74 & 0.488 \\
\hline Number of years respondent lived in Lusaka & 18.86 & 1.645 & 95 & 16.08 & 1.233 & 74 & 0.0926 \\
\hline Couple has electricity & 0.316 & 0.0739 & 95 & 0.378 & 0.0554 & 74 & 0.398 \\
\hline Formally married & 0.874 & 0.0480 & 95 & 0.919 & 0.0360 & 74 & 0.347 \\
\hline Number of days in past 7 days couple has sex & 2.011 & 0.249 & 92 & 1.865 & 0.185 & 74 & 0.558 \\
\hline Number of days in past month couple has sex & 8.170 & 0.863 & 94 & 8.865 & 0.646 & 74 & 0.422 \\
\hline Number of children husband has with other women & 0.301 & 0.0718 & 93 & 0.297 & 0.0536 & 74 & 0.958 \\
\hline \multicolumn{8}{|l|}{ Frequency at which couple has talked about contraception in last } \\
\hline Couple has ever disagreed on number of children & 0.253 & 0.0679 & 95 & 0.257 & 0.0509 & 74 & 0.952 \\
\hline Couple has ever disagreed on contraception use & 0.126 & 0.0535 & 95 & 0.149 & 0.0401 & 74 & 0.677 \\
\hline Have used contraceptive method without husband's knowledge & 0.189 & 0.0569 & 95 & 0.122 & 0.0427 & 74 & 0.235 \\
\hline Husband drinks at least 2 to 3 times a week & 0.432 & 0.0754 & 95 & 0.324 & 0.0566 & 74 & 0.157 \\
\hline Husband has ever threatened physical violence & 0.537 & 0.0778 & 95 & 0.541 & 0.0583 & 74 & 0.962 \\
\hline Wife ever pressured to have sex & 0.484 & 0.0775 & 95 & 0.581 & 0.0581 & 74 & 0.213 \\
\hline Husband does budgeting & 0.158 & 0.0563 & 95 & 0.149 & 0.0422 & 74 & 0.870 \\
\hline Husband decides major purchases & 0.674 & 0.0745 & 95 & 0.608 & 0.0558 & 74 & 0.380 \\
\hline Joint F Statistic & & & & & & & 28.07 \\
\hline \multirow[t]{3}{*}{ P-value } & & & & & & & 0.461 \\
\hline & \multicolumn{3}{|c|}{ Individual Treatment } & \multicolumn{3}{|c|}{ Couple Treatment } & \\
\hline & Mean & Standard Error & $\overline{\mathrm{N}}$ & Mean & Standard Error & $\overline{\mathrm{N}}$ & $\overline{\text { P-Value }}$ \\
\hline \multicolumn{8}{|l|}{ Panel B } \\
\hline Using any method at baseline & 0.884 & 0.0518 & 95 & 0.863 & 0.0389 & 73 & 0.683 \\
\hline Number of living children & 2.674 & 0.243 & 95 & 2.973 & 0.183 & 73 & 0.221 \\
\hline Using injectable at baseline & 0.274 & 0.0625 & 95 & 0.123 & 0.0470 & 73 & 0.0172 \\
\hline Using pill at baseline & 0.326 & 0.0744 & 95 & 0.370 & 0.0559 & 73 & 0.559 \\
\hline Using a hormonal contraceptive at baseline & 0.600 & 0.0774 & 95 & 0.507 & 0.0582 & 73 & 0.230 \\
\hline Has ever used an injectable contraceptive method & 0.516 & 0.0772 & 95 & 0.392 & 0.0579 & 74 & 0.110 \\
\hline Months since last birth (at recruitment) & 15.20 & 1.012 & 95 & 15.63 & 0.761 & 73 & 0.671 \\
\hline Husband's age (reported by husband) & 33.35 & 1.252 & 95 & 34.04 & 0.938 & 74 & 0.580 \\
\hline Husband's highest schooling attained (reported by husband) & 8.968 & 0.440 & 95 & 8.743 & 0.330 & 74 & 0.609 \\
\hline Husband's ideal number of children (reported by husband) & 4.053 & 0.320 & 94 & 4.392 & 0.239 & 74 & 0.291 \\
\hline Husband's average monthly income (1,000 USD) (reported by husband) & 0.119 & 0.0382 & 95 & 0.163 & 0.0286 & 74 & 0.250 \\
\hline Wife earned money in previous month & 0.298 & 0.0747 & 94 & 0.466 & 0.0560 & 73 & 0.0259 \\
\hline Husband works $40+$ hours & 0.600 & 0.0784 & 90 & 0.592 & 0.0586 & 71 & 0.914 \\
\hline Wife ever pressured violently to have sex & 0.118 & 0.0501 & 93 & 0.110 & 0.0375 & 73 & 0.862 \\
\hline Husband decides savings & 0.653 & 0.0753 & 95 & 0.595 & 0.0564 & 74 & 0.442 \\
\hline Husband holds the money & 0.147 & 0.0578 & 95 & 0.181 & 0.0436 & 72 & 0.567 \\
\hline
\end{tabular}


Table A.4: Summary Statistics for Households in Which Both Husband and Wife Don't Want a Child in the Next 2 Years

\begin{tabular}{|c|c|c|c|c|c|c|c|}
\hline & \multicolumn{3}{|c|}{ Individual Treatment } & \multicolumn{3}{|c|}{ Couple Treatment } & \multirow[b]{2}{*}{ P-Value } \\
\hline & Mean & Standard Error & $\mathrm{N}$ & Mean & Standard Error & $\mathrm{N}$ & \\
\hline Highest schooling attained & 6.386 & 0.320 & 184 & 6.505 & 0.224 & 192 & 0.709 \\
\hline Husband's highest schooling attained (reported by wife) & 9.449 & 0.280 & 198 & 9.337 & 0.201 & 187 & 0.688 \\
\hline Ideal number of children & 3.915 & 0.163 & 213 & 4.165 & 0.116 & 206 & 0.127 \\
\hline Age & 28.53 & 0.653 & 213 & 28.99 & 0.466 & 205 & 0.486 \\
\hline Husband's age (reported by wife) & 35.29 & 0.767 & 192 & 35.55 & 0.546 & 187 & 0.741 \\
\hline Husband's ideal number of children (reported by wife) & 4.088 & 0.201 & 205 & 4.450 & 0.145 & 191 & 0.0719 \\
\hline Has ever used a modern contraceptive method & 0.915 & 0.0305 & 213 & 0.864 & 0.0218 & 206 & 0.0928 \\
\hline Wife has monthly income & 0.376 & 0.0476 & 213 & 0.393 & 0.0340 & 206 & 0.712 \\
\hline Wife knows when she is most fertile & 0.146 & 0.0343 & 199 & 0.116 & 0.0245 & 190 & 0.383 \\
\hline Wife wants to become pregnant in following 2 years & 0 & 0 & 213 & 0 & 0 & 206 & . \\
\hline Age wife married & 19.36 & 0.414 & 211 & 19.07 & 0.295 & 205 & 0.496 \\
\hline Catholic & 0.225 & 0.0409 & 213 & 0.223 & 0.0291 & 206 & 0.960 \\
\hline $\begin{array}{l}\text { Comparison of happiness with other women in region } \\
(1=\text { very unhappy, } 5=\text { very happy })\end{array}$ & 3.587 & 0.0881 & 213 & 3.641 & 0.0628 & 206 & 0.541 \\
\hline $\begin{array}{l}\text { Comparison of health with other women in region } \\
(1=\text { very poor, } 5=\text { excellent })\end{array}$ & 3.629 & 0.0735 & 213 & 3.709 & 0.0524 & 206 & 0.280 \\
\hline Number of years respondent lived in Lusaka & 18.62 & 1.068 & 213 & 19.21 & 0.763 & 205 & 0.576 \\
\hline Couple has electricity & 0.380 & 0.0473 & 213 & 0.364 & 0.0338 & 206 & 0.732 \\
\hline Formally married & 0.878 & 0.0323 & 213 & 0.874 & 0.0230 & 206 & 0.898 \\
\hline Number of days in past 7 days couple has sex & 1.933 & 0.158 & 209 & 1.966 & 0.113 & 204 & 0.837 \\
\hline Number of days in past month couple has sex & 7.410 & 0.514 & 210 & 7.618 & 0.366 & 204 & 0.686 \\
\hline Number of children husband has with other women & 0.309 & 0.0456 & 207 & 0.300 & 0.0324 & 203 & 0.849 \\
\hline $\begin{array}{l}\text { Frequency at which couple has talked about contraception in last } \\
\text { year }\end{array}$ & 1.845 & 0.103 & 213 & 1.748 & 0.0736 & 206 & 0.345 \\
\hline Couple has ever disagreed on number of children & 0.117 & 0.0303 & 213 & 0.0971 & 0.0216 & 206 & 0.504 \\
\hline Couple has ever disagreed on contraception use & 0.0798 & 0.0271 & 213 & 0.0874 & 0.0193 & 206 & 0.780 \\
\hline Have used contraceptive method without husband's knowledge & 0.136 & 0.0320 & 213 & 0.107 & 0.0228 & 206 & 0.359 \\
\hline Husband drinks at least 2 to 3 times a week & 0.404 & 0.0483 & 213 & 0.427 & 0.0344 & 206 & 0.628 \\
\hline Husband has ever threatened physical violence & 0.493 & 0.0488 & 213 & 0.563 & 0.0348 & 206 & 0.151 \\
\hline Wife ever pressured to have sex & 0.488 & 0.0490 & 213 & 0.519 & 0.0349 & 206 & 0.525 \\
\hline Husband does budgeting & 0.131 & 0.0339 & 213 & 0.146 & 0.0242 & 205 & 0.661 \\
\hline Husband decides major purchases & 0.618 & 0.0478 & 212 & 0.602 & 0.0341 & 206 & 0.738 \\
\hline Joint F Statistic & & & & & & & 17.36 \\
\hline $\mathrm{P}$-value & & & & & & & 0.941 \\
\hline
\end{tabular}

